\title{
Validation of Recipes for Double-Blind Placebo-Controlled Challenges With Milk, Egg White, and Hazelnut
}

\author{
González-Mancebo E1, Alonso Díaz de Durana MD², García Estringana Y², \\ Meléndez Baltanás $\mathrm{A}^{1}$, Rodriguez-Alvarez $\mathrm{M}^{3}$, de la Hoz Caballer $\mathrm{B}^{4}$, \\ del Prado $\mathrm{N}^{5}$, Fernández-Rivas $\mathrm{M}^{3}$
}

\author{
'Allergy Department, Hospital Universitario de Fuenlabrada, Madrid, Spain \\ ${ }^{2}$ Allergy Department, Hospital Universitario Fundación Alcorcón, Madrid, Spain \\ ${ }^{3}$ Allergy Department, Hospital Clínico San Carlos, IdISSC, Madrid, Spain \\ ${ }^{4}$ Allergy Department, Hospital Universitario Ramón y Cajal, IRYCIS, Madrid, Spain \\ ${ }^{5}$ Clinical Epidemiology Unit, Preventive Medicine Department, Hospital Clínico San Carlos, IdISSC, Madrid, \\ Spain
}

J Investig Allergol Clin Immunol 2017; Vol. 27(1): 40-45

doi: 10.18176/jiaci.0084

\begin{abstract}
Background: The double-blind, placebo-controlled food challenge (DBPCFC) is considered the definitive diagnostic test for food allergy. Nevertheless, validated recipes for masking the foods are scarce, have not been standardized, and differ between centers. Sensory evaluation techniques such as the triangle test are necessary to validate the recipes used for DBPCFC.

Methods: We developed 3 recipes for use in DBPCFC with milk, egg white, and hazelnut and used the triangle test to validate them in a 2-phase study in which 197 volunteers participated. In each phase, participants tried 3 samples (2 active-1 placebo or 2 placebo-1 active) and had to identify the odd one. In phase 1, the 3 samples were given simultaneously, whereas in phase 2, the 3 samples of foods that failed validation in phase 1 were given sequentially. A visual analog scale (VAS) ranging from 1 to 10 was used to evaluate how much participants liked the recipes.

Results: In phase 1, the egg white recipe was validated ( $n=89$ volunteers, $38.9 \%$ found the odd sample, $P=.16$ ). Milk and hazelnut recipes were validated in phase 2 (for both foods, $n=30$ participants, $36.7 \%$ found the odd sample, $P=.36$ ). Median VAS scores for the 3 recipes ranged from 6.6 to 9.7 .

Conclusions: We used sensory testing to validate milk, egg white, and hazelnut recipes for use in DBPCFC. The validated recipes are easy to prepare in a clinical setting, provide the equivalent of 1 serving dose, and were liked by most participants.
\end{abstract}

Key words: Double-blind placebo-controlled food challenge. Egg white. Food allergy. Hazelnut. Milk. Recipe. Sensory test. Triangle test. Validation.

\section{Resumen}

Introducción: La provocación oral doble ciego controlada con placebo (PODCCP) es la prueba diagnóstica definitiva en alergia a alimentos. A pesar de ello hay pocas recetas validadas, que además no están estandarizadas y difieren entre centros. Para poder validar recetas para PODCCP es necesario utilizar pruebas sensoriales como el test del triángulo.

Métodos: Se han desarrollado tres recetas para PODCCP con leche, clara de huevo y avellana, que se han validado mediante el test del triángulo en un estudio en dos fases con 197 voluntarios. En cada fase los participantes probaban 3 muestras ( 2 activo- 1 placebo o 2 placebo-1 activo) y debían identificar la diferente. En la fase 1 las 3 muestras se presentaban simultáneamente, mientras que en la fase 2 las muestras de las recetas no validadas en la fase 1 eran presentadas secuencialmente a los voluntarios. Los participantes evaluaron de 1 a 10 su apreciación de las recetas en una escala visual analógica (EVA).

Resultados: En la fase 1 la receta de clara de huevo fue validada ( $n=90$ sujetos, 38,9\% identificaron la muestra diferente, $p=0,16)$. Las recetas de leche y avellana fueron validadas en la fase 2 (cada receta fue probada por 30 sujetos, y en cada una el 36,7\% identificaron la muestra diferente, $p=0,36)$. La mediana de la puntuación en la EVA de las 3 recetas osciló entre 6,6 y 9,7. 
Conclusiones: Hemos validado mediante pruebas sensoriales recetas para PODCCP con leche, clara de huevo y avellana. Las recetas validadas son fáciles de realizar en el entorno asistencial, proporcionan una cantidad equivalente a una ración y fueron apreciadas por la mayoría de los participantes.

Palabras clave: Provocación oral doble ciego controlada con placebo. Clara de huevo. Alergia a alimentos. Avellana. Leche. Receta. Prueba sensorial. Test del triángulo. Validación.

\section{Introduction}

The oral food challenge is the only test that confirms a diagnosis of food allergy. Its aim is to confirm or exclude the patient's reactivity to a specific food. There are 3 types of oral food challenges: open challenge, single-blind placebocontrolled food challenge, and double-blind placebo-controlled food challenge (DBPCFC). In each of them, increasing doses of the food under investigation are given progressively at time intervals. A blinded oral challenge consists of the administration of food that is masked in order to hide its consistency, smell, color, and flavor. When the challenge is placebo-controlled, some doses contain only food and other doses only placebo, and administration is determined randomly on 2 separate days. The challenge is usually based on fresh food, whose features are masked in vehicles (juices, smoothies) or semisolids. They are very useful for assessing symptoms, especially chronic or subjective ones, since the patient does not know when he or she is receiving active food or placebo. The DBPCFC is considered the gold standard in diagnosing adverse food reactions [1-3] and is the only accepted test in research. Nevertheless, it is a nonstandardized test, and each clinical group develops its own masking recipes and dosing procedures or protocols. To perform a DBPCFC, the food must be truly blinded. Sensory testing to identify differences between samples has been used to validate food recipes for DBPCFCs [4-11]. Discrimination tests are commonly used in sensory science for application in market research and the food industry. They are used to discriminate whether there is a difference (or similarity) between 2 or more samples. The test most frequently used is the triangle test, whose objective is to establish differences between 2 samples (ie, placebo and active food), irrespective of which attribute differs between samples [12-14].

The Committee of Food Allergy of the Spanish Society of Allergy and Clinical Immunology (SEAIC) set a target of developing recipes for performing blinded oral challenges with the foods most often implicated in allergic reactions. The recipes had to be easy in order to facilitate implementation in clinical practice, applicable to both children and adults, and able to deliver a full serving. Furthermore, they had to be validated using sensory methods. In this manuscript, we present the results of the validation process after applying the triangle test to recipes for masking milk, egg white, and hazelnut in DBPCFC.

Table 1. Milk, Egg White, and Hazelnut Recipes

\begin{tabular}{|c|c|c|}
\hline Recipes & Active Sample Ingredients & Placebo Sample Ingredients \\
\hline Milk & $\begin{array}{l}250 \mathrm{~mL} \text { of whole UHT cow's milk } \\
2 \text { scoops of soy milk powder }(9 \mathrm{~g}) \\
2 \text { scoops of milk hydrolysate powder }(9 \mathrm{~g}) \\
4 \text { scoops of soluble cacao }(18 \mathrm{~g}) \\
4 \text { scoops of vanilla sugar }(18 \mathrm{~g}) \\
\text { Red food coloring }\end{array}$ & $\begin{array}{l}250 \mathrm{~mL} \text { of UHT soy milk } \\
2 \text { scoops of soy milk powder }(9 \mathrm{~g}) \\
2 \text { scoops of milk hydrolysate powder }(9 \mathrm{~g}) \\
4 \text { scoops of soluble cacao }(18 \mathrm{~g}) \\
4 \text { scoops of vanilla sugar }(18 \mathrm{~g}) \\
\text { Red food coloring }\end{array}$ \\
\hline Egg white & $\begin{array}{l}34 \mathrm{~mL} \text { of pasteurized liquid egg white } \\
206 \mathrm{~mL} \text { of chocolate soymilk } \\
2 \text { scoops of milk hydrolysate }(9 \mathrm{~g}) \\
2 \text { scoops of vanilla sugar }(9 \mathrm{~g})\end{array}$ & $\begin{array}{l}240 \mathrm{~mL} \text { of UHT chocolate soy milk } \\
2 \text { scoops of milk hydrolysate }(9 \mathrm{~g}) \\
2 \text { scoops of vanilla sugar }(9 \mathrm{~g})\end{array}$ \\
\hline Hazelnut ${ }^{\mathrm{b}}$ & $\begin{array}{l}8 \text { hazelnuts }(10 \mathrm{~g}) \\
1 \text { can of pickled tuna paté }(82 \mathrm{~g}) \\
10 \mathrm{~mL} \text { vinegar } \\
10 \mathrm{~g} \text { wheat bran } \\
1 \text { scoop of brown sugar }(4.5 \mathrm{~g})\end{array}$ & $\begin{array}{l}1 \text { can of pickled tuna paté } \\
5 \mathrm{~mL} \text { vinegar } \\
10 \mathrm{~g} \text { wheat bran } \\
2 \text { scoops of brown sugar }(9 \mathrm{~g})\end{array}$ \\
\hline
\end{tabular}

a34 $\mathrm{mL}$ of pasteurized liquid egg white equals one whole egg.

bThe paste is eaten spread on toast.

Ingredients: tuna, tapioca, potato, milk, sunflower oil, salt, and vinegar. 


\section{Methods}

\section{Recipes}

The foods masked were milk, egg white, and hazelnut. The ingredients used to prepare the recipes are summarized in Table 1. The same ingredients and procedures were used to prepare the active food and placebo recipes. Additional requirements were an acceptable taste, sufficient challenge dose (total amount of allergenic food equivalent to 1 serving) in a suitable volume for children and adults, and a good correlation between the sensory properties of the placebo and the active food.

\section{Study Design}

The recipes were validated using the triangle test. The volunteers tasted 3 samples of each food, distributed randomly between active food (A) and placebo (P). Each sample was labelled with a 3-digit code. Six possible combinations of A and P (AAP, APA, PAA, PPA, PAP, APP) were offered to the participants with equal frequency in a random order. Participants were told that 2 samples were similar and 1 was different, asked to assess the samples in the order provided, and not allowed to retest the samples [13]. Crackers and water were used as palate cleansers after each sample. The participants were told to fill out a questionnaire where they were required to identify the odd one (they were forced to choose 1 option even if they could not find differences between them). In addition, the participants had to select the characteristics that made the sample different in terms of color, taste, texture, and smell. Finally, the participants evaluated how much they liked a recipe on a visual analog scale (VAS) ranging from 0 to 10 .

The study was performed in 2 phases. In phase 1 , participants tested 2 different foods and received the 3 samples of each tested food simultaneously (all together on a tray). In phase 2, participants tested only 1 food and received the 3 samples sequentially (one after the other), which is another way of applying the triangle test [12-14]. Phase 2 was planned only for those foods that failed validation in phase 1 . These 2 variations of the test are methodologically sound and can be used indifferently in the validation of recipes [12-14].

\section{Participants}

Phase 1 of the study was performed within the framework of the 2010 annual conference of the SEAIC. Individuals attending this meeting were invited to participate in the sensorial evaluation of these recipes in a controlled environment. They had all received information in their conference pack and approached the sensory testing area voluntarily.

The inclusion criteria were as follows: age $\geq 18$ years; nonsmoker; no food allergy; no active respiratory disease, rhinitis, anosmia, or impaired olfaction; no active respiratory allergy; no oropharyngeal disease; fasting during the previous 2 hours. Participants with lactose intolerance and celiac disease were excluded.

Phase 2 of the study was performed in the Allergy Units of Hospital Universitario de Fuenlabrada, Fuenlabrada, Spain and Hospital Universitario Fundación Alcorcon, Alcorcón, Spain. The same inclusion and exclusion criteria were applied.

\section{Statistics}

For phase 1, with a $33.3 \%$ probability of identifying the odd sample by chance $(P=.33), 10 \%$ accuracy, and $95 \%$ confidence, the sample size was estimated at 85 participants. For phase 2, with the same conditions, the sample size was estimated at 30 participants for each food (60 in total).

In phase 1, each participant was randomly assigned to a pair of foods (egg-milk, egg-hazelnut, milk-egg, milk-hazelnut, hazelnut-egg, hazelnut-milk) and to 1 of the 6 possible combinations of A and P (AAP, APA, PAA, PPA, PAP, APP) based on a uniform random distribution. In phase 2 , participants tasted only 1 food with the same 6 possible combinations of A and $\mathrm{P}$ also based on a uniform random distribution.

For each food, the percentage of participants who identified the odd sample was calculated, as was the right-tail probability of observing $\mathrm{k}$ correct answers (or more) in a binomial distribution in which the parameters were the number of participants who tasted each food and a $33.3 \%$ probability of getting it right by chance. The right-tail probability is chosen because we were interested in detecting high frequencies of correct answers. In case A and P were similar (food well masked), the right-tail probability was not expected to be significantly different $(P \geq .05)$ from $P=.33$. In the case that $\mathrm{A}$ and $\mathrm{P}$ were different (food not adequately masked), the right-tail probability was expected to be significantly different $(P<.05)$.

The percentage of participants who found differences in color, taste, texture, and smell were compared between those who identified the odd sample and those who did not using a chi-square test. A $P$ value $<.05$ was considered significant.

\section{Results}

A total of 137 volunteers ( 86 women [62.8\%] and 51 men [37.2\%], mean [SD] age of 42.6 [9.5] years) participated in the phase 1 evaluation of the recipes. Each participant was randomly given 2 of the 3 foods to taste. Hazelnut and milk were evaluated by 92 individuals, and egg white by 90 . Eightyone participants $(59.1 \%)$ were physicians (allergists or allergy residents), $26(19.0 \%)$ were allergy nurses, and $30(21.9 \%)$ had other professions. The odd sample was identified by 56 out of $92(60.9 \%)$ individuals in the milk recipe $(P<.001), 35$ out of $90(38.9 \%)$ in the egg white recipe $(P=.16)$, and 41 of 92 $(44.6 \%)$ in the hazelnut recipe $(P=.02)$. Table 2 shows the differences between the samples in terms of color, taste, texture, and smell, as reported by the participants who identified the odd sample and those who did not.

No significant differences in the rate of correct answers were observed for any of the 3 recipes according to profession or sex. Among those who identified the odd sample, a similar rate of men and women observed differences in color, smell, taste, and texture between the samples. From all those who selected the option "all the samples look the same" (42 participants) but were forced to choose 1 as the odd one, $21.4 \%$ chose the first sample, $38.1 \%$ the second one, and $40.5 \%$ the third one $(P=.131)$. In the VAS evaluation of how much the participants liked each recipe (ranging from 0 ["I don't like it"] to 10 ["I like it very much"]), a median (IQR) of 6.6 (4.4-7.7) 
Table 2. Phase 1 Evaluation: Differences Between Samples Reported by the Volunteers Who Identified the Active Food Sample (Correct Answer) and Volunteers Who Did Not (Incorrect Answer)

\begin{tabular}{|c|c|c|c|c|c|c|c|c|c|c|c|c|}
\hline & \multicolumn{3}{|c|}{ Difference in Color } & \multicolumn{3}{|c|}{ Difference in Smell } & \multicolumn{3}{|c|}{ Difference in Taste } & \multicolumn{3}{|c|}{ Difference in Texture } \\
\hline & $\begin{array}{l}\text { Correct } \\
\text { Answer }\end{array}$ & $\begin{array}{l}\text { Incorrect } \\
\text { Answer }\end{array}$ & $P$ & $\begin{array}{l}\text { Correct } \\
\text { Answer }\end{array}$ & $\begin{array}{l}\text { Incorrect } \\
\text { Answer }\end{array}$ & $P$ & $\begin{array}{l}\text { Correct } \\
\text { Answer }\end{array}$ & $\begin{array}{l}\text { Incorrect } \\
\text { Answer }\end{array}$ & $P$ & $\begin{array}{l}\text { Correct } \\
\text { Answer }\end{array}$ & $\begin{array}{l}\text { Incorrect } \\
\text { Answer }\end{array}$ & $P$ \\
\hline Milk recipe & $\begin{array}{c}15 / 56 \\
(26.8 \%)\end{array}$ & $\begin{array}{c}3 / 36 \\
(8.3 \%)\end{array}$ & $<.05$ & $\begin{array}{c}6 / 56 \\
(10.7 \%)\end{array}$ & $\begin{array}{c}6 / 36 \\
(16.7 \%)\end{array}$ & NS & $\begin{array}{c}48 / 56 \\
(85.7 \%)\end{array}$ & $\begin{array}{c}28 / 36 \\
(77.8 \%)\end{array}$ & NS & $\begin{array}{c}7 / 56 \\
(12.5 \%)\end{array}$ & $\begin{array}{c}7 / 36 \\
(19.4 \%)\end{array}$ & NS \\
\hline Egg white recipe & $\begin{array}{l}2 / 34^{\mathrm{a}} \\
(5.8 \%)\end{array}$ & $\begin{array}{c}1 / 55 \\
(1.8 \%)\end{array}$ & NS & $\begin{array}{c}3 / 34 \\
(8.8 \%)\end{array}$ & $\begin{array}{c}9 / 55 \\
(16.4 \%)\end{array}$ & NS & $\begin{array}{c}23 / 34 \\
(67.6 \%)\end{array}$ & $\begin{array}{c}36 / 55 \\
(65.4 \%)\end{array}$ & NS & $\begin{array}{c}7 / 34 \\
(20.5 \%)\end{array}$ & $\begin{array}{l}5 / 55 \\
(9 \%)\end{array}$ & NS \\
\hline Hazelnut recipe & $\begin{array}{c}8 / 41 \\
(19.5 \%)\end{array}$ & $\begin{array}{c}2 / 51 \\
(3.9 \%)\end{array}$ & $<.05$ & $\begin{array}{c}6 / 41 \\
(14.6 \%)\end{array}$ & $\begin{array}{c}4 / 51 \\
(7.8 \%)\end{array}$ & NS & $\begin{array}{c}35 / 41 \\
(85.4 \%)\end{array}$ & $\begin{array}{c}39 / 51 \\
(76.4 \%)\end{array}$ & NS & $\begin{array}{c}13 / 41 \\
(31.7 \%)\end{array}$ & $\begin{array}{c}7 / 51 \\
(13.7 \%)\end{array}$ & $<.05$ \\
\hline
\end{tabular}

Abbreviation: NS, nonsignificant $(P \geq .05)$

${ }^{a} n=34$, because 1 of the 35 participants who identified the odd sample in egg white recipe did not provide answers for the differences in color, smell, taste, and texture.

was found for the milk recipe, 6.6 (4.9-7.6) for the egg white recipe, and 7.3 (5.6-8.4) for the hazelnut recipe.

Phase 2 was carried out 2 months later for milk and hazelnut, since $60.9 \%$ and $44.6 \%(P<.05)$ of the participants in phase 1 , respectively, identified the odd sample for these foods. Phase 2 was performed at the Allergy Unit of Hospital Universitario de Fuenlabrada, where the milk recipe was tested, and at the Allergy Unit of Hospital Universitario Fundación Alcorcón, where the hazelnut recipe was evaluated. A total of 30 volunteers (physicians, nurses, and other hospital staff) at each center participated in the evaluation of the recipes (60 participants in total: 43 women [71.7\%] and 17 men [28.3\%] with a mean age of 42.6 [8.5] years). Each participant evaluated only 1 food. Nineteen participants (31.7\%) were physicians, 15 (25.0\%) were nurses, and 26 (43.3\%) had other professions.

The odd sample was identified by 11 out of 30 individuals $(36.7 \%)$ in the milk recipe $(P=.36)$ and 11 of 30 individuals $(36.7 \%)$ in the hazelnut recipe $(P=.36)$. No differences between samples in terms of color, taste, texture, and smell were found between participants who identified the odd sample and those who did not (Table 3). No significant differences in the rate of correct answers were observed by profession or sex for either of the 2 recipes on the VAS evaluation of how much the participants liked each recipe (ranging from 0 ["I don't like it"] to 10 ["I like it very much"]); a median of 7.2 (6.08.0) was found for the milk recipe and $9.7(7.8-10)$ for the hazelnut recipe.

\section{Discussion}

In this study, we validated recipes for milk, egg white, and hazelnut to be used in DBPCFC. These foods are commonly involved in allergic reactions.

Recipes to be used in blinded challenges should be rigorously validated by a panel of professional and wellselected panelists [12-14]. However, this is a very expensive and time-consuming procedure that requires special facilities and is affordable to very few groups $[4,8,9]$. Our study included 197 volunteers related to the field of allergy, 141 of whom $(71.6 \%)$ were allergists, allergy residents, or allergy nurses who understood the aim and relevance of the study. With the evaluation of active and placebo foods by these volunteers separated by a few minutes, we consider that it is easier to detect differences between samples than in routine clinical practice, where active and placebo foods are given on 2 separate days. Therefore, although not performed by professional panelists - a limitation of the study - the procedure could be an appropriate approach for the validation of our recipes.

Two fundamental requirements must be met when masking a food for DBPCFCs. The first is that the allergenic food be properly dressed so as not to distinguish between active food and placebo, thus minimizing possible psychological effects. The objective of the triangle test for validation of recipes for DBPCFC is to determine whether 2 samples (active food and

Table 3. Phase 2 Evaluation: Differences Between Samples Reported by the Volunteers Who Identified the Active Food Sample (Correct Answer) or Not (Incorrect Answer)

\begin{tabular}{|c|c|c|c|c|c|c|c|c|c|c|c|c|}
\hline & \multicolumn{3}{|c|}{ Difference in Color } & \multicolumn{3}{|c|}{ Difference in Smell } & \multicolumn{3}{|c|}{ Difference in Taste } & \multicolumn{3}{|c|}{ Difference in Texture } \\
\hline & Correct & Incorrect & $P$ & Correct & Incorrect & $P$ & Correct & Incorrect & $P$ & Correct & Incorrect & $P$ \\
\hline & Answer & Answer & & Answer & Answer & & Answer & Answer & & Answer & Answer & \\
\hline Milk recipe & $\begin{array}{l}0 / 11 \\
(0 \%)\end{array}$ & $\begin{array}{c}1 / 19 \\
(5.2 \%)\end{array}$ & NS & $\begin{array}{l}0 / 11 \\
(0 \%)\end{array}$ & $\begin{array}{c}4 / 19 \\
(21 \%)\end{array}$ & NS & $\begin{array}{c}11 / 11 \\
(100 \%)\end{array}$ & $\begin{array}{c}14 / 19 \\
(73.6 \%)\end{array}$ & NS & $\begin{array}{l}1 / 11 \\
(9 \%)\end{array}$ & $\begin{array}{c}3 / 19 \\
(15.7 \%)\end{array}$ & NS \\
\hline Hazelnut recipe & $\begin{array}{l}0 / 11 \\
(0 \%)\end{array}$ & $\begin{array}{c}3 / 19 \\
(15.7 \%)\end{array}$ & NS & $\begin{array}{l}0 / 11 \\
(0 \%)\end{array}$ & $\begin{array}{c}2 / 19 \\
(10.5 \%)\end{array}$ & NS & $\begin{array}{c}11 / 11 \\
(100 \%)\end{array}$ & $\begin{array}{c}15 / 19 \\
(78.9 \%)\end{array}$ & NS & $\begin{array}{l}0 / 11 \\
(0 \%)\end{array}$ & $\begin{array}{c}4 / 19 \\
(21 \%)\end{array}$ & NS \\
\hline
\end{tabular}

Abbreviation: NS, nonsignificant (P>.05). 
placebo) are sufficiently similar that the volunteer does not know which is which. As the volunteers were testing 3 samples of each recipe, the probability of chance identification is $1 / 3$. A success rate greater than $33 \%$ means that 1 or more samples are probably different. When the number of participants who observed differences between the samples is compared with that of those who did not, a statistically nonsignificant result means that the differences may be attributed to chance and implies that both samples (active/placebo) are sufficiently similar.

The second fundamental requirement when masking a food for DBPCFC is that a sufficient amount of the allergenic food must be masked in a total volume appropriate for the patient. The recipes tested in this study contained the equivalent of 1 serving of the allergenic food, were easy to prepare, and used readily available ingredients, thus facilitating implementation of the recipes in daily clinical practice.

In the phase 1 evaluation, close to $39 \%$ of the participants found the odd sample in the egg white recipe $(P=.16)$. Since this figure is close to the percentage of hits that can be attributed to chance $(33.3 \%)$, we can conclude that there were no differences between samples in the egg white recipe. Furthermore, participants did not find differences in the color, taste, smell, or texture of the samples (Table 2).

The milk and hazelnut recipes did not reach the validation stage in the phase 1 study, because $60.9 \%$ and $44.6 \%$, respectively, of the participants identified the odd sample $(P<.05)$, thus suggesting that there were differences between the active food and the placebo. The volunteers appreciated differences in the color of the milk samples and in the color and texture of the hazelnut samples (Table 2).

In the phase 1 evaluation, the 3 samples were presented to the participants together, and, curiously, color was one of the main characteristics that enabled identification of the odd sample in milk and hazelnut. However, in clinical practice, patients or their relatives, as well as the blind evaluators, cannot observe (or recall) small differences in color or in other characteristics, since active and placebo meals are given on different days. For this reason, we conducted a second evaluation of the milk and hazelnut recipes following the same methodology with a single modification: volunteers were offered the samples sequentially (one after the other) and could not compare their color. This posed a situation closer to that of DBPCFC in clinical practice, where patients receive placebo or the active meal on different days. Furthermore, this is also a correct way to apply the triangle test: when samples show slight differences in appearance they may be offered sequentially without invalidating the test [12-14].

The results for the assessment of overall acceptance of the recipes (how much the participants liked them according to the VAS) were very good. Median VAS scores for the 3 recipes ranged from 6.6 to 9.7 .

In summary, we developed easy-to-perform recipes to blind full-serving doses of egg white, milk, and hazelnut for DBPCFC and we validated them using the triangle test. These recipes can be used in DBPCFCs with both children and adults. The hazelnut recipe can be adapted to blind other tree nuts or peanut, although sensory testing would be needed.

Validated challenge recipes facilitate implementation of DBPCFC in clinical practice, thus ensuring a reliable diagnosis by minimizing the bias generated by the subjectivity of patients and clinical evaluators.

\section{Funding}

This study was partly funded by the Spanish Society of Allergy and Clinical Immunology (SEAIC).

\section{Conflicts of Interest}

The authors declare that they have no conflicts of interest.

\section{References}

1. Bindslev-Jensen $C$, Ballmer-Weber BK, Bengtsson U, Blanco $C$, Ebner C, Hourihane J, Knulst AC, Moneret-Vautrin DA, Nekam K, Niggemann B, Osterballe M, Ortolani C, Ring J, Schnopp C, Werfel T; European Academy of Allergology and Clinical Immunology Position paper EAACI. Standardization of food challenges in patients with immediate reactions to foods-position paper from the European Academy of Allergology and Clinical Immunology. Allergy. 2004;59:690-7.

2. Nowak-Wegrzyn A, Assa'ad AH, Bahna SL, Bock SA, Sicherer $\mathrm{SH}$, Teuber SS. Adverse Reactions to Food Committee of American Academy of Allergy, Asthma \& Immunology. Work Group report: oral food challenge testing. J Allergy Clin Immunol. 2009:123:365-83.

3. Sampson HA, Gerth van Wijk R, Bindslev-Jensen $C$, Sicherer S, Teuber SS, Burks AW, Dubois AE, Beyer K, Eigenmann PA, Spergel JM, Werfel T, Chinchilli VM. Standardizing doubleblind, placebo-controlled oral food challenges: American Academy of Allergy, Asthma \& Immunology-European Academy of Allergy and Clinical Immunology PRACTALL consensus report. J Allergy Clin Immunol. 2012;130:1260-74.

4. Vlieg-Boerstra BJ, Bijleveld CMA, van der Heide S, Beusekamp BJ, Wolt-Plompen SAA, Kukler J, Brinkman J, Duiverman EJ, Dubois AEJ. Development and validation of challenge materials for double-blind, placebo-controlled food challenges in children. J Allergy Clin Immunol. 2004;113:341-6.

5. Ronteltap A, van Schaik J, Wensing M, Rynja FJ, Knulst $A C$ de Vries $\mathrm{JH}$. Sensory testing of recipes masking peanut or hazelnut for double-blind placebo-controlled food challenges. Allergy. 2004;59:457-60.

6. Van Odijk J, Ahlstedt S, Bengtsson U, Borres MP, Hulthen L. Double-blind placebo-controlled food challenge for peanut allergy the efficiency of blinding procedures and the allergenic activity of peanut availability in the recipes. Allergy. 2005;60:602-5.

7. Vassilopoulou E, Douladiris N, Sakellariou A, Cortes SV, Sinaniotis A, Rivas MF, Papadopoulos NG. Evaluation and standardisation of different matrices used for DBPCFC to fish. J Hum Nutr Diet. 2010;23:544-9.

8. Vlieg-Boerstra BJ, Herpertz I, Pasker L, van der Heide S, Kukler J, Jansink C, Vaessen W, Beusekamp BJ, Dubois AE. Validation of novel recipes for double-blind, placebo-controlled food challenges in children and adults. Allergy. 2011;66:948-54.

9. Cochrane SA, Salt LJ, Wantling E, Rogers A, Coutts J, BallmerWeber BK, Fritsche P, Fernández-Rivas $M$, Reig I, Knulst $A$, Le TM, Asero R, Beyer K, Golding M, Crevel R, Clare Mills EN, Mackie AR. Development of a standardized low-dose double- 
blind placebo-controlled challenge vehicle for the EuroPrevall project. Allergy. 2012;67:107-13.

10. Libbers L, Flokstra-de Blok BMJ, Vlieg-Boerstra BJ, van der Heide S, van der Meulen GN, Kukler J, Kerkhof M, Dubois AEJ. No matrix effect in DBPC egg challenges in egg allergic children. Clin Exp Allergy. 2013;43:1067-70.

11. Winberg $A$, Nordström $L$, Strinnholm A, Nylander $A$, Jonsäll $A$, Rönmark E, West CE. New validated recipes for double-blind placebo-controlled low-dose food challenges. Pediatr Allergy Immunol. 2013;24:282-7.

12. Meilgaard, MC, Carr BT, and Civille GV. Sensory Evaluation Techniques, Fourth Edition. CRC press, 2006.

13. Kemp SE, Hollowood T and Hort J. Sensory Evaluation: A Practical Handbook, First Edition. Wiley-Blackwell, 2009.

14. Lawless HT, Heymann H. Sensory Evaluation of Food: Principles and Practices. Second edition. Springer Science \& Business Media, LCC 2010.
Manuscript received April 2, 2016; accepted for
publication May 24, 2016 .

\section{- Montserrat Fernández-Rivas}

Hospital Clínico San Carlos

Servicio de Alergia

c/ Prof. Martín Lagos, s/n

20040 Madrid

Spain

E-mail:

mariamontserrat.fernandez@salud.madrid.org 